\title{
Cardiac magnetic resonance imaging and gadolinium angiography for neonates and small infants: a 10-year single institutional experience
}

\author{
Sheela Rangamani $i^{*}$, Joby Varghese ${ }^{3}$, James M Hammel $^{2}$, Scott E Fletcher ${ }^{1}$, Kim F Duncan², David A Danford ${ }^{1}$, \\ Shelby Kutty ${ }^{1}$
}

From 15th Annual SCMR Scientific Sessions

Orlando, FL, USA. 2-5 February 2012

\section{Background}

With increasing applications of cardiac magnetic resonance (CMR) for definitive diagnosis of congenital heart disease (CHD) in infants, safety of this technology is of particular interest in this age group. We report our tenyear experience with CMR in neonates and small infants with particular focus on the safety profile and incidence of adverse events.

\section{Methods}

Clinical, anesthesia and nursing records of all patients (pts) $<120$ days of age who underwent CMR were reviewed. Variables including cardiac diagnosis, study duration, anesthesia type and agents used, prostaglandin E1 (PGE1) dependence and gadolinium (Gd) use were recorded. Serially recorded temperature, systemic saturation, and cardiac rhythm were analyzed. Primary outcome measure was any adverse event (AE) during or $<24$ hours after the procedure, including minor AE such as hypothermia (axillary temperature $\leq 95 \mathrm{~F}$ ), desaturation ( $\mathrm{SpO} 2$ drop $\geq 10 \%$ below baseline) and bradycardia (heart rate $\leq 100 / \mathrm{min}$ ). Secondary outcome measure was unplanned overnight hospitalization of out-pts.

\section{Results}

Pts ( $\mathrm{n}=143 ; 74$ male, 69 female) had a median age of 7 days (1-117), and 98 were $\leq 30$ days at the time of CMR. The median weight was $3.4 \mathrm{~kg}$ (1.4-6) and body surface area $0.22 \mathrm{~m} 2(0.13-0.32)$. There were $118(83 \%)$ in-pts (108 receiving intensive care) and $25(17 \%)$ out-pts. Indications were assessment of aortic $\operatorname{arch}(n=57)$,

'University of Nebraska/Creighton University, Joint Division of Pediatric

Cardiology, Children's Hospital and Medical Center, Omaha, NE, USA

Full list of author information is available at the end of the article complex CHD ( $n=41)$, pulmonary veins $(n=15)$, vascular ring $(n=8)$, intracardiac mass $(n=8)$, pulmonary artery $(n=7)$, ventricular volume $(n=4)$, and systemic veins $(\mathrm{n}=3)$. CMR was performed using a 1.5-T scanner (Philips), and a commercially available coil. CMR utilized general anesthesia (GA) in 86 pts, deep sedation in 50 and no sedation in 7. Gd angiography was performed in 136 pts. Fifty-nine pts were PGE1 dependent and 39 had a univentricular circulation. Among pts on PGE1, $43(74 \%)$ received GA and 10 (26\%) had deep sedation. Twelve pts (8\%) had AE, 1 major and 11 minor. Nine of the12 pts had GA, and 3 had deep sedation. The single major AE was respiratory arrest after chloral hydrate sedation in a neonate (resuscitated without sequelae). Minor AE included desaturations $(n=2)$, hypothermia $(\mathrm{n}=5)$, bradycardia $(\mathrm{n}=2)$, and bradycardia with hypoxemia $(n=2)$. Incidence of minor AE was $9 \%$ for in-pts (vs. $4 \%$ for out-pts), and $8 \%$ for neonates (vs. $9 \%$ in pts $\geq 30$ days). Incidence of minor AE was similar between PGE1 dependent infants and non-PGE1 group. There were no AE related to Gd angiography. Of 25 out-pts, 5 (20\%) were admitted for overnight observation due to desaturations.

\section{Conclusions}

CMR imaging can be accomplished safely in neonates and infants $\leq 120$ days for a wide range of pre surgical cardiac indications. Incidence of $\mathrm{AE}$ was unrelated to pt age, complexity of heart disease, type of anesthesia and PGE1 dependence.

\section{Funding}

None. 


\section{Author details}

${ }^{1}$ University of Nebraska/Creighton University, Joint Division of Pediatric

Cardiology, Children's Hospital and Medical Center, Omaha, NE, USA.

${ }^{2}$ Division of Cardiovascular Surgery, University of Nebraska/Creighton

University, Children's Hospital and Medical Center, Omaha, NE, USA. ${ }^{3}$ Division

of Anesthesia, Children's Hospital and Medical Center, Omaha, NE, USA.

Published: 1 February 2012

doi:10.1186/1532-429X-14-S1-057

Cite this article as: Rangamani et al:: Cardiac magnetic resonance

imaging and gadolinium angiography for neonates and small infants: a

10-year single institutional experience. Journal of Cardiovascular Magnetic

Resonance 2012 14(Suppl 1):057.

Submit your next manuscript to BioMed Central and take full advantage of:

- Convenient online submission

- Thorough peer review

- No space constraints or color figure charges

- Immediate publication on acceptance

- Inclusion in PubMed, CAS, Scopus and Google Scholar

- Research which is freely available for redistribution

Submit your manuscript at www.biomedcentral.com/submit 